\title{
Making a quality endoscopy report
}

\author{
Mark R Borgaonkar MD MSc
}

$I^{n}$ 2012, the Canadian Association of Gastroenterology (CAG) published guidelines to address a broad range of issues pertaining to the safety and quality of endoscopic service provision in Canada, including reporting standards for endoscopic procedures (1). In the current issue of the Canadian Journal of Gastroenterology, Beaulieu et al (2) (pages 286-292) discuss the selection criteria and rationale underlying the specific elements recommended for inclusion in endoscopic reports.

At the most fundamental level, a procedure report is a form of communication. The needs of various relevant parties must be considered when preparing the report. We often consider only the referring physician but must realize that others also rely on the report, such as other treating physicians, other health care providers, the patients themselves, the health authority and, possibly, legal representatives. In many ways, the report has greatest relevance for the endoscopists themselves because they will make direct use of the report and will refer to it during subsequent patient encounters to guide management.

Because a procedure report serves multiple purposes for multiple readers, there is a large amount of detailed information that it must contain. Many endoscopists rely on their own routine for inclusion of items in their reports; however, this nonsystematic approach can lead to omission of important items. Furthermore, the necessary components of an endoscopic procedure report have not previously been defined.

Beaulieu et al (2) address all of these issues. Working as a subcommittee of the CAG Safety and Quality Indicators in Endoscopy Consensus Group, the authors systematically searched the literature for items to consider for inclusion in endoscopy reports. These were then voted on by all 35 members of the CAG Consensus Group to determine the final recommendations. The result is 24 elements recommended for inclusion in all endoscopy reports.

The importance of these elements is self-evident. However, some are worth a closer look. Inclusion of pertinent negative findings is critical to a complete report. For example, an upper gastrointestinal endoscopy performed for reflux symptoms must include a statement about the presence or absence of Barrett's esophagus. In practice, the absence of such information may lead to the procedure being repeated. Standardized reporting can resolve this problem. Similarly, inclusion of a clear statement regarding postprocedure diagnosis and management recommendations is of tremendous importance. Failure to do so can be a cause of confusion for subsequent patient care.

The authors make a strong case for electronic reporting to improve the systematic collection of data and to facilitate data analysis. The value of such a system also includes mandatory reporting fields and forcing the consistent use of terminology/rating scales (such as the quality of bowel preparation). The upfront costs of electronic reporting systems may appear to be prohibitive but show a positive financial benefit after three years (3). Endoscopists may initially find that electronic systems are more time consuming, but with more use and familiarity, such systems may become time saving.

Standardized reporting will also help with data collection pertaining to quality measures such as cecal intubation, withdrawal time and adenoma detection (1). These data must be recorded in reports so that they can be tracked and used to improve the quality of endoscopic performance.

The article by Beaulieu et al (2) is an important step forward for endoscopic services in Canada. It provides us the required elements of every report and highlights the importance of standardized electronic reporting. Moreover, this work facilitates the move toward a national database of procedure reports, which would provide a wealth of knowledge for endoscopists and improve health care for Canadians.

\section{REFERENCES}

1. Armstrong D, Barkun A, Bridges R, et al. Canadian Association of Gastroenterology consensus guidelines on safety and quality indicators in endoscopy. Can J Gastroenterol 2012;26:17-31.

2. Beaulieu D, Barkun AN, Dude C, Tinmouth J, Halle P, Martel M. Endoscopy reporting standards. Can J Gastroenterol 2013:27:286-92.

3. Groenen MJ, Ajodhia S, Wynstra JY, et al. A cost-benefit analysis of endoscopy reporting methods: Handwritten, dictated, and computerized. Endoscopy 2009;41:603-9.

Department of Medicine, Memorial University, St John's, Newfoundland and Labrador

Correspondence: Dr Mark Borgaonkar, Department of Medicine, Memorial University of Newfoundland, 300 Prince Phillip Drive, St John's,

Newfoundland and Labrador A1B 3V6. Telehone 709-777-8072, fax 709-777-7054, e-mail markb@mun.ca

Received and accepted for publication March 18, 2013 


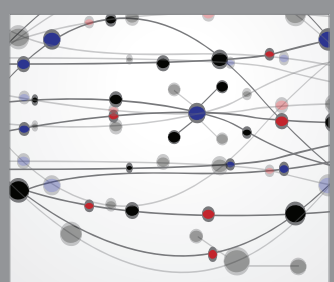

The Scientific World Journal
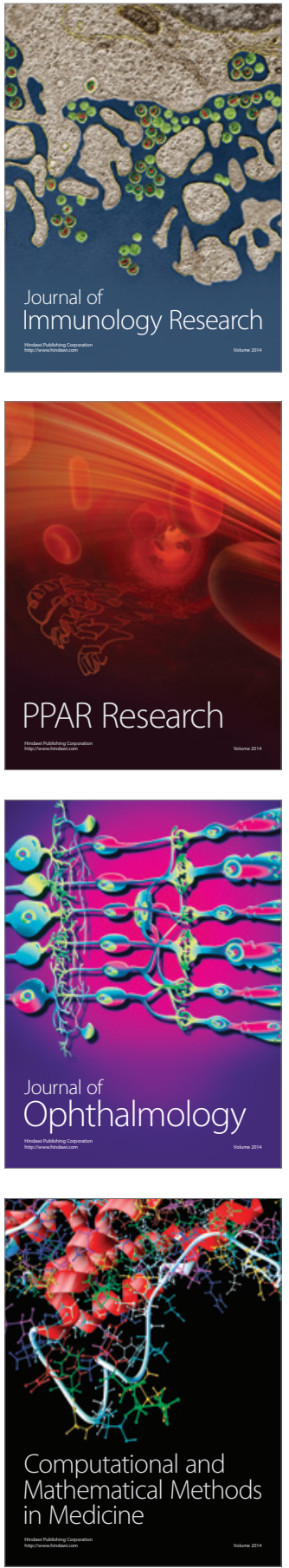

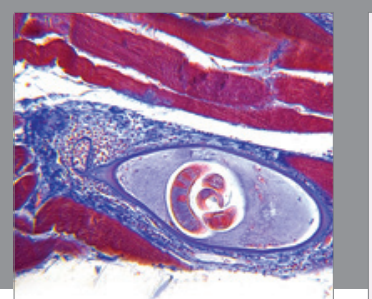

Gastroenterology Research and Practice

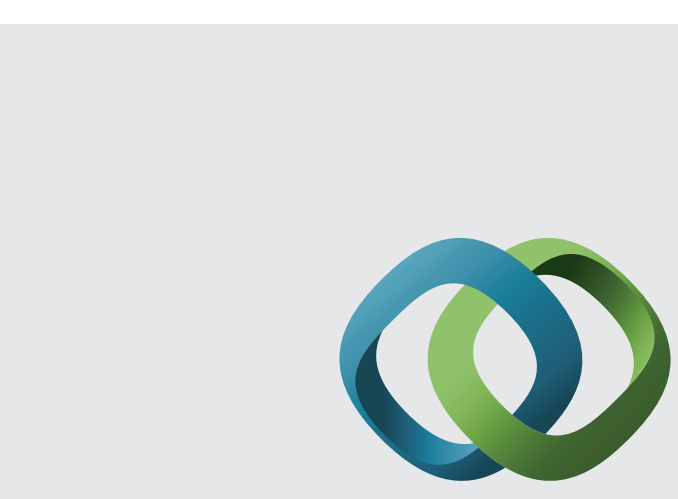

\section{Hindawi}

Submit your manuscripts at

http://www.hindawi.com
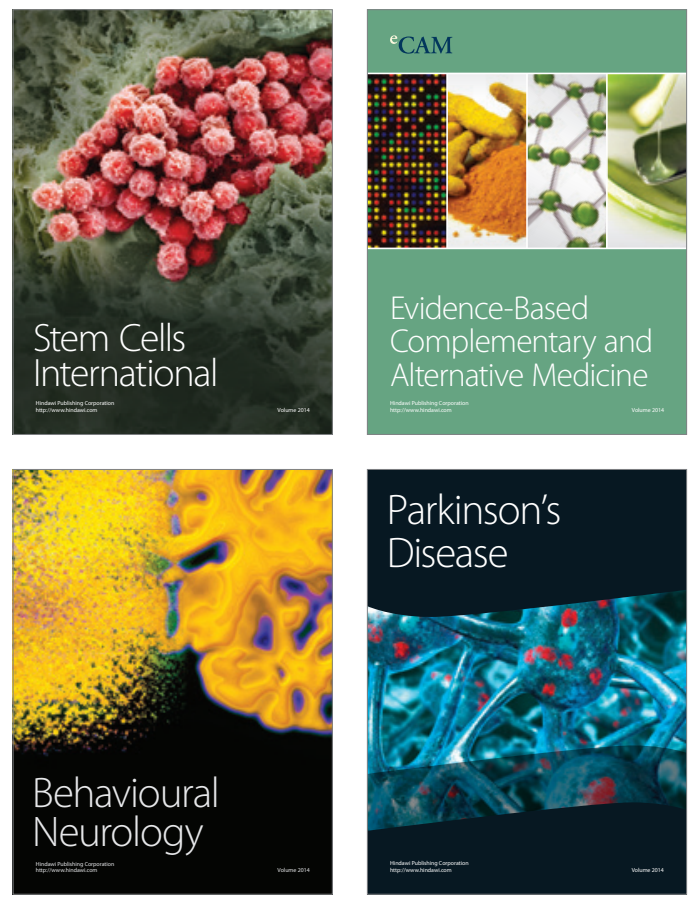
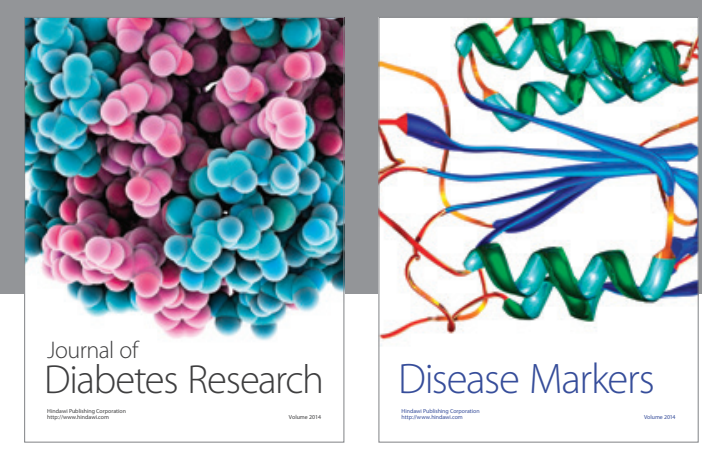

Disease Markers
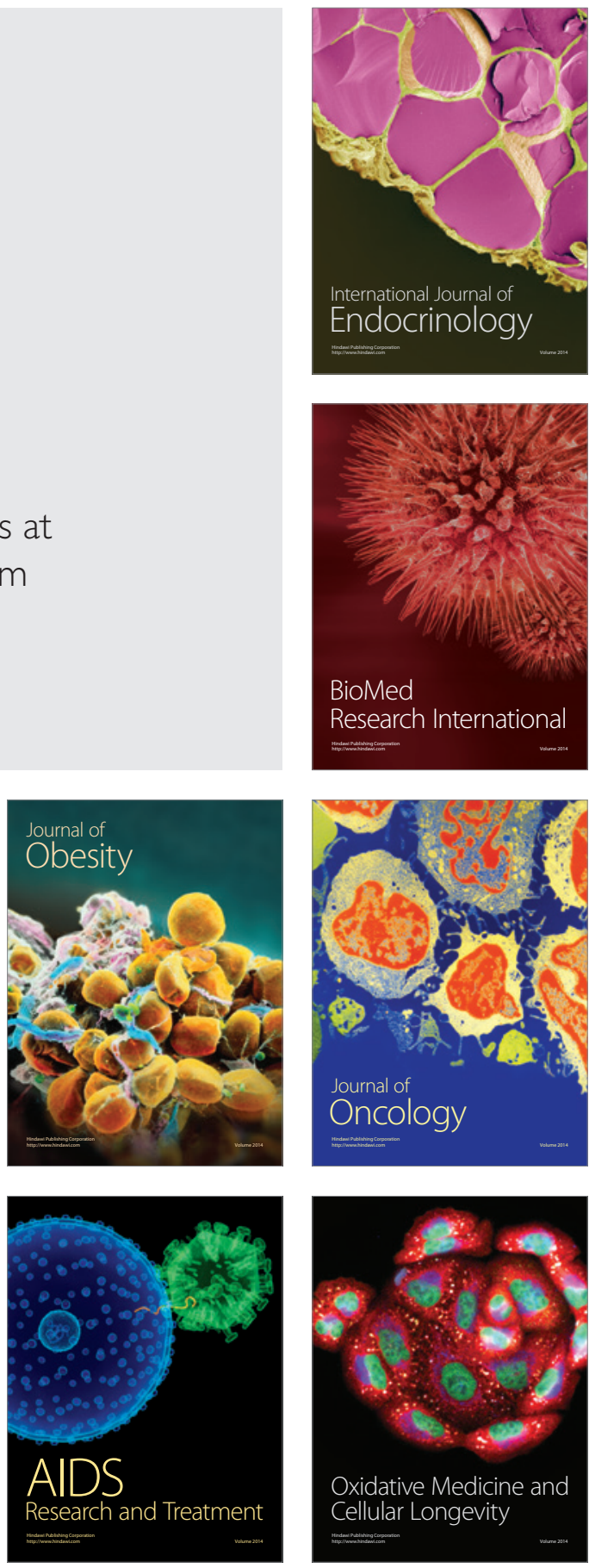